\title{
A presença de Jean-Jacques Rousseau no discurso educacional de John Dewey ${ }^{1}$
}

\author{
The presence of Jean-Jacques Rousseau in the educational discourse of John Dewey
}

\author{
Marcus Vinícius da Cunha* \\ Roberta Aline Sbrana ${ }^{* *}$
}

\section{Resumo}

O objetivo deste artigo é examinar a presença de concepções educacionais de Jean-Jacques Rousseau no livro Democracia e educação, de John Dewey. Para isso, são analisadas duas temáticas fundamentais em ambos os pensadores: suas reflexões acerca da sociedade vigente, em que se inclui a educação nela ministrada, e suas proposições em defesa de novas práticas educativas. A investigação é feita por intermédio da análise retórica proposta por Perelman e Olbrechts-Tyteca, metodologia que permite extrair de um texto os argumentos centrais do autor e identificar as estratégias argumentativas por ele utilizadas. As semelhanças discursivas encontradas nos dois filósofos sugerem a possibilidade de integrá-los à tradição retórica oriunda dos sofistas, cujas práticas visavam à valorização do indivíduo no processo de sua educação e à liberação de seus impulsos para desenvolver as capacidades de deliberar e agir de modo inteligente. $\mathrm{O}$ artigo apresenta como conclusão que tanto Rousseau quanto Dewey podem ser postos em confronto direto com as tendências da pedagogia contemporânea que concebem a educação como uma mercadoria que deve servir não à fruição da vida, mas ao propósito de garantir à pessoa sucesso profissional e ascensão na hierarquia social e, à sociedade, progresso econômico e bom posicionamento na ordenação global das nações.

Palavras-chave: Análise retórica. Educação contemporânea. Jean-Jacques Rousseau. John Dewey.

\section{Abstract}

The purpose of this article is to examine the presence of educational conceptions of Jean-Jacques Rousseau in the book Democracy and Education of John Dewey. For this, two fundamental themes are analyzed in both thinkers: their reflections on the current society, which includes the education offered in it, and their propositions in defense of new educational practices. The research is done through the rhetorical analysis proposed by Perelman and Olbrechts-Tyteca, methodology that allows to extract from a text the central arguments of the author and to identify the argumentative strategies used by him. The discursive similarities found in the two philosophers suggest the possibility of integrating them into the rhetorical tradition of the sophists, whose practices aimed at valuing the individual in the process of his education and the liberation of his impulses to develop the ability to deliberate and act intelligently. The article concludes that both Rousseau and Dewey can be put in direct confrontation with the tendencies of contemporary pedagogy that conceive education as a commodity that should serve not the enjoyment of life, but to the purpose of guaranteeing to the person professional success and ascension in the social hierarchy, and to society, economic progress and good positioning in the global ordering of nations.

Keywords: Rhetorical analysis. Contemporary pedagogy. Jean-Jacques Rousseau. John Dewey.

Recebido em 19/06/2017 - Aprovado em 04/12/2017

http://dx.doi.org/10.5335/rep.v25i1.8033

Doutor em Educação pela Universidade de São Paulo e livre-docente em Psicologia da Educação pela Universidade Estadual Paulista. Pesquisador do Conselho Nacional de Desenvolvimento Científico e Tecnológico e professor associado da Faculdade de Filosofia, Ciências e Letras de Ribeirão Preto, Universidade de São Paulo, atuando no curso de Pedagogia e no Programa de Pós-Graduação em Educação. E-mail: mvcunha2@hotmail.com

** Mestre em Educação pela Universidade de São Paulo. Cursa o doutorado no Programa de Pós-Graduação em Educação Escolar da Faculdade de Ciências e Letras de Araraquara, Universidade Estadual Paulista. Bolsista da Fundação de Amparo à Pesquisa do Estado de São Paulo (Fapesp). E-mail: robertaasbrana@gmail.com 


\section{Introdução}

Para analisar em que medida e de que modo John Dewey (1859-1952) incorpora o pensamento educacional de Jean-Jacques Rousseau (1712-1778), teríamos que examinar todas as menções feitas pelo primeiro ao segundo, o que implicaria identificar citações diretas e indiretas distribuídas em um conjunto de trabalhos que, na publicação da Southern Illinois University, ocupa nada menos que 17 volumes, contendo livros, ensaios, cartas e conferências elaborados entre 1882 e o ano da morte do filósofo americano. A tarefa torna-se substancialmente facilitada quando circunscrita à Democracia e educação (1959b), obra capital no que tange às proposições educacionais deweyanas.

Em Democracia e educação, Rousseau é mencionado em quatro momentos, a começar pelo quinto capítulo, durante a discussão das ideias de Hegel, apresentadas como um avanço perante as teses do filósofo genebrino por reconhecerem o valor das instituições sociais na formação do intelecto (DEWEY, 1959b, p. 64). A segunda menção, no sétimo capítulo, sugere haver grande influência de Platão sobre Rousseau, no que diz respeito à concepção de natureza vigente no século XVIII (DEWEY, 1959b, p. 98). A terceira aparece um uma nota de rodapé acrescida ao texto principal do mesmo capítulo, com o propósito de discutir se o ideal de formação contido em Emílio é concentrado na formação do homem ou - em sintonia com as tendências daquele século - do cidadão (DEWEY, 1959b, p. 100-101).

Essas três primeiras menções são breves, circunstanciadas por temáticas específicas, não se dedicando a examinar amplamente as teses rousseaunianas. A quarta aparição de Rousseau em Democracia e educação, porém, constitui parte relevante do nono capítulo, que analisa o problema das finalidades da educação: educar é promover o desenvolvimento natural do aprendiz, em respeito às suas qualidades e necessidades individuais, ou produzir a eficiência social, em consonância com as exigências impostas pela sociedade? Na primeira seção do referido capítulo, Rousseau é apresentado como propositor de fins educacionais condizentes com a natureza do indivíduo, concluindo Dewey (1959b, p. 129), no entanto, que a solução do problema, para aquele filósofo, reside em organizar um ambiente capaz de aproveitar adequadamente as tendências naturais do aluno, o que comporta uma crítica à ordem social vigente e ao modo como nela são educados as crianças e os jovens.

Nesse último momento, passagem que em pouco ultrapassa oito págias da edição brasileiro do livro, as considerações de Dewey são bastante sugestivas, mas insuficientes para encerrar a questão, ou seja, para concluir quais concepções de Rousseau são acolhidas pela filosofia deweyana. Por isso, propomos adotar outra 
abordagem para cumprir essa tarefa, considerando que a presença de concepções rousseaunianas no discurso educacional de Dewey pode ser identificada por meio da análise das noções fundamentais contidas em Democracia e educação. Para isso, elegeremos examinar, tanto nessa obra quanto em obras de Rousseau, duas temáticas assumidas como essenciais para compreender as proposições educacionais de ambos os pensadores: suas reflexões acerca da sociedade vigente, em que se inclui a educação nela ministrada, e suas proposições em defesa de novas práticas educativas.

Para examinar essas noções, empregaremos os recursos da análise retórica, seguindo as indicações de Perelman e Olbrechts-Tyteca (2005), cuja base encontra-se na obra de Aristóteles (2011), metodologia que permite extrair de um texto os argumentos centrais do autor - denominado orador - e identificar as estratégias discursivas por ele utilizadas. Essa abordagem segue o pressuposto de que um texto, quando tornado público, pretende mobilizar as disposições intelectuais e emocionais de determinada audiência, seus possíveis leitores, impulsionando-os a agir segundo as ideias que constituem o cerne do discurso proferido. Todo texto com essas qualidades integra as disputas teóricas e políticas da área de conhecimento em que o orador e sua audiência estão posicionados (CUNHA, 2005, p. 195).

A análise de textos que discorrem sobre assuntos educacionais permite supor dois tipos de audiência: uma, específica, composta por certo segmento de pessoas envolvidas imediatamente com o tema em pauta, como professores, alunos e suas famílias; outra, universal, representada por todos os que tenham algum interesse em questões relativas à educação, quaisquer que sejam as suas intenções (CUNHA, 2015, p. 3). Quando se trata de comparar discursos proferidos por oradores distanciados no tempo, como faremos neste trabalho, deve-se considerar o peso dos condicionantes de época, determinantes das motivações particulares de cada autor e das disposições de seus leitores.

A obra Democracia e educação foi publicada em 1916 nos Estados Unidos da América, em meio a sensíveis transformações ocasionadas pelo avanço do capitalismo, pela ascensão de movimentos populares e pelo crescente conflito social. A Primeira Guerra Mundial, a busca de novas bases para a democracia e o surgimento de teorias educacionais comprometidas com alterações nos ambientes cultural e político compõem o cenário de profundos questionamentos sobre o conceito de cidadania (CAMBI, 1999, p. 378-379). Tendo dirigido uma experiência educacional inovadora na Universidade de Chicago entre os anos de 1894 e 1904 e estando desde 1906 vinculado à Universidade de Colúmbia, Dewey ocupou-se com a investigação da gênese dos problemas de sua sociedade, procurando oferecer alternativas para a sua superação (AMARAL, 1990, p. 32-33). 
A época de Rousseau é caracterizada por importantes mudanças nas esferas política e econômica do mundo europeu, como também no plano das ideias, por influência dos processos de laicização e emancipação (CAMBI, 1999, p. 323). Sob o reinado de Luís XV, a França era palco dos processos de enfraquecimento do poder absolutista e de afirmação da burguesia como classe social. O descontentamento e a revolta crescentes contra as arbitrariedades do regime levaram intelectuais de diversas orientações teóricas ao posicionamento comum que os qualificava como iluministas (PISSARRA, 2002, p. 8-10). Boto (1996, p. 21) analisa que o movimento iluminista concebia a ação educativa como ferramenta de transformação do homem e da sociedade, assumindo uma "perspectiva totalizadora e profética". Foi nesse contexto que Rousseau escreveu as obras que iremos analisar neste trabalho: Discurso sobre as ciências e as artes (2002a) e Discurso sobre a origem e os fundamentos da desigualdade entre os homens (2002b), publicadas pela primeira vez respectivamente em 1750 e 1755; O contrato social (2003) e Emílio ou da educação (2004), ambas de 1762.

Como se pode notar por esses breves apontamentos, os condicionantes de época impõem cuidados especiais a qualquer tentativa de comparação entre os dois filósofos. Mas há, certamente, circunstâncias que os aproximam, como o fato de ambos terem atuado em contextos de intensas crises social e política, nos quais reinava a incerteza sobre o futuro, e, diante disso, terem desenvolvido obras destinadas a mudar a situação existente, visando à construção de uma nova sociedade; e, mais ainda, por terem acreditado na educação como meio imprescindível para realizar esse intento. É sobre tais coincidências - sem desprezar eventuais divergências que se aplica a análise retórica, buscando investigar as estratégias discursivas que cada um dos pensadores julgou adequadas para argumentar em defesa de suas teses diante de suas respectivas audiências.

Empregando essa metodologia e utilizando como fontes o livro Democracia e educação, considerado o mais representativo do pensamento educacional deweyano, e os trabalhos de Rousseau já indicados, a primeira seção deste artigo focalizará a temática da sociedade e da educação vigentes, ao passo que a segunda será voltada ao exame das proposições pedagógicas elaboradas pelos dois filósofos. A terceira seção proporá uma visão de conjunto. Além de oferecer contribuições ao estudo de cada um dos pensadores - e, em especial, ao estudo comparativo de suas ideias -, esta investigação visa discutir a possibilidade de integrá-los a certa tradição discursiva no campo da educação, cujos desenvolvimentos podem ser úteis para refletirmos sobre a atualidade, conforme procuraremos elaborar em nossas considerações finais. 


\section{A sociedade e a educação vigentes}

Um dos argumentos centrais de Democracia e educação expressa uma crítica à sociedade contemporânea, caracterizada por Dewey (1959b, p. 280) como dividida em classes sociais, uma culta, outra inculta, uma baseada no trabalho útil, e outra, no ócio, na contemplação. Essa realidade contribui para dividir os membros da coletividade entre aqueles que se ocupam de atividades que exigem o mínimo de reflexão, pensamento autônomo e apreciação estética, e aqueles cujas ações envolvem diretamente o uso da inteligência e a atribuição de controlar os demais.

Como fruto dessa divisão, Dewey (1959b, p. 280) explica que a educação reproduz o distanciamento entre "cultura e utilidade", promovendo duas concepções de educação igualmente distanciadas: uma "liberal ou intelectual", destinada a tratar questões teóricas e a desenvolver a inteligência, e uma "baixa ou mecânica", voltada exclusivamente a assuntos práticos e à produção material. Nessa última, a reflexão é dispensável, prevalecendo a repetição mecânica de determinadas habilidades (DEWEY, 1959b, p. 278). Enquanto a primeira valoriza a atividade considerada racional, a segunda prepara somente para ocupações manuais. A consequência é que o trabalho se torna rigidamente identificado com "interesses materiais", ao passo que o lazer se desloca para a esfera dos "interesses ideais", o que impossibilita a livre comunicação e o compartilhamento de experiências e interesses entre os indivíduos, cenário que, por sua vez, inviabiliza a existência de um modo de vida mais equilibrado - a democracia, como veremos adiante (DEWEY, 1959b, p. 276).

No Discurso sobre as ciências e as artes, também conhecido como Primeiro Discurso, Rousseau (2002a, p. 14) também apresenta uma crítica à sociedade de sua época, caracterizando-a pela ausência de virtudes e pela prevalência de vícios, como a traição, a desconfiança e a frieza, o que contribui para a corrupção dos costumes e para uma vida de aparências. Essa situação é fomentada pelo deslumbramento dos homens perante as ciências e as artes, que passaram a ser utilizadas com o objetivo de atender a interesses individuais, nutrindo a vaidade, o luxo e a riqueza, sem promover benefícios sociais. Nesse cenário degradado, certos conhecimentos são qualificados como superiores por serem elaborados por homens cultos, embora apresentem pouca utilidade para os demais cidadãos, uma vez que se distanciam da vida social (ROUSSEAU, 2002a, p. 27).

Diante de uma ordem social marcada pela desigualdade, a educação apenas "orna o espírito e corrompe o juízo" (ROUSSEAU, 2002a, p. 33-34), requerendo incontáveis despesas e prestando-se a ensinar tudo às crianças, exceto o que precisam saber e fazer quando se tornam homens. O que se ensina são discursos admiráveis que garantem aos aprendizes a aquisição de talentos considerados apra- 
zíveis, como fama e poder, sem qualquer preocupação com o desenvolvimento de qualidades favoráveis à coletividade, como a humildade, a união, o reconhecimento de direitos e deveres e a garantia da igualdade e da liberdade. O resultado desse processo é a formação de músicos, poetas, pintores, físicos, mas não de cidadãos (ROUSSEAU, 2002a, p. 35).

No Discurso sobre a origem e o fundamento da desigualdade entre os homens, chamado Segundo Discurso, Rousseau (2002b, p. 235) explica que, nessa configuração social, são produzidos cidadãos ricos e pobres, sempre aumentando a desigualdade entre os extremos. O predomínio dessa desigualdade impede que a vida social seja constituída por princípios democráticos, como a igualdade de direitos e interesses entre governantes e governados, o cultivo do bem comum, o compartilhamento e a fruição de uma vida livre; enfim, tudo o que poderia contribuir para desenvolver virtudes, ao invés de vícios (ROUSSEAU, 2002b, p. 136).

Segundo a análise retórica, tanto os argumentos de Rousseau quanto os de Dewey operam a desqualificação da sociedade vigente, estratégia comumente utilizada em argumentações que pretendem valorizar a proposição de ideias alternativas. Quando a intenção do orador consiste em classificar um termo como superior a outro, seu discurso usualmente promove a desvalorização do segundo, indicando o que julga inadequado ou o que aparenta estar nele incorreto (PERELMAN; OLBRECHTS-TYTECA, 2005, p. 144). Dewey julga impróprios os dualismos instaurados na base da vida social; para Rousseau, a sociedade é ruim por causa da desigualdade. Ambos desqualificam a ordem vigente com o intuito de valorizar outra ordem, uma forma de vida coletiva alicerçada em princípios democráticos, apresentada como possuidora de qualidades superiores à existente.

Para sustentar a desqualificação pretendida, os discursos de ambos enfatizam a necessidade de superar os males sociais da época, buscando persuadir suas audiências quanto à possibilidade de agir nessa direção. Dewey (1959b, p. 282) afirma que, para suplantar as divisões sociais, filosóficas e educacionais características de seu tempo, é necessário promover mudanças nos âmbitos moral e material. Tais mudanças somente serão concretizadas com a articulação de uma "sociedade verdadeiramente democrática", na qual todos os cidadãos realizem atividades práticas úteis à vida comum e tenham a oportunidade de desfrutar de atividades nobres voltadas ao lazer. A efetivação dessa sociedade, porém, requer a transformação das condições educacionais em vigor.

Para Rousseau (2003, p. 9), a superação da ordem social somente será possível pela elaboração de consensos diferentes daqueles que ora existem, os quais contribuem para a manutenção das desigualdades entre os homens, tornando-os acorrentados, apesar de terem nascido livres. A ordem social deve estar alicerçada em 
consensos que permitam a todos os cidadãos utilizar suas forças e sua liberdade, que são as primeiras ferramentas da igualdade. A elaboração desses novos consensos sociais será afiançada pelo estabelecimento de um contrato social que permitirá a associação entre os homens, implicando, ainda, a necessária reorganização da educação (ROUSSEAU, 2003, p. 20-21).

Na ênfase dada pelos dois filósofos à necessidade de ultrapassar o existente, é possível identificar o uso do argumento de superação, recurso discursivo que, segundo Perelman e Olbrechts-Tyteca, permite ao orador "insistir na possibilidade de ir sempre mais longe num certo sentido, sem que se entreveja um limite nessa direção" (2005, p. 327-328). Trata-se de uma forma de argumentar que propõe à audiência a possibilidade de ir além do que existe, deixando para trás uma situação indesejada, como se oferecesse um "trampolim" que permite a mobilização em prol do que é almejado. Tanto em Dewey quanto em Rousseau, essa mobilização se traduz em ações voltadas à criação de uma nova ordem social fundamentada em princípios democráticos.

Para sustentar sua argumentação sobre essa nova ordem, Dewey utiliza a estratégia discursiva denominada definição: democracia é uma "forma de vida associada, de experiência conjunta e mutuamente comunicada" (1959b, p. 93). Esse "modo de viver" é mais do que uma forma de governo, pois prevê que os interesses dos indivíduos estejam associados reciprocamente, e que "o progresso ou a readaptação" ocupe o primeiro plano, uma vez que a sociedade se vê em permanente mudança. Com essa definição, a democracia assume um "significado pedagógico", vinculando-se ao desenvolvimento integral das disposições constitutivas dos indivíduos. A relevância educacional desse conceito reside no interesse em promover uma "educação deliberada e sistemática".

Direcionamento discursivo semelhante encontra-se em Rousseau (2003), que também define a democracia ao tecer considerações sobre o contrato social. Sua primeira definição ressalta a necessidade de "encontrar uma forma de associação que defenda e proteja com toda a força comum a pessoa e os bens de cada associado, e pela qual cada um, unindo-se a todos, só obedeça, contudo, a si mesmo e permaneça tão livre quanto antes" (ROUSSEAU, 2003, p. 20-21). Boto explica que, na sociedade regida pelo contrato rousseauniano, a democracia é definida como um "modo de viver coletivo" (2010, p. 14). Essa definição de democracia, pautada essencialmente no valor da coletividade, afeta as reflexões rousseaunianas relativas ao modo ideal de governo, definido pelo filósofo como aquele que conta com a maioria do povo, instituindo "cidadãos magistrados" (ROUSSEAU, 2003, p. 81-82). Tais cidadãos serão incumbidos de executar as leis segundo os consensos estabelecidos pelo coletivo, tendo sempre em vista o bem comum (ROUSSEAU, 2003, p. 72). ${ }^{2}$ 
A definição - recurso utilizado tanto por Dewey quanto por Rousseau - é uma estratégia discursiva que, segundo Perelman e Olbrechts-Tyteca, consiste em "fornecer o sentido verdadeiro, o sentido real da noção, oposto ao seu uso habitual" (2005, p. 504). Ao propor um novo modo de definir determinado objeto, em detrimento do modo geralmente aceito, o orador produz uma dissociação nocional, de tal maneira que as concepções por ele privilegiadas sejam aprovadas pela audiência, em oposição ao que é usualmente adotado. É o que temos quando os dois filósofos definem democracia como modo de viver, contrariando o sentido comum, geralmente vinculado às formas de governo. ${ }^{3}$

O uso da dissociação nocional produz pares filosóficos, o que, segundo Perelman e Olbrechts-Tyteca (2005, p. 473), viabiliza a polarização e a hierarquização entre duas ideias, revelando, assim, as inclinações do orador, ou seja, a tese por ele defendida em determinado campo de reflexão. A disposição gráfica de um par filosófico indica que o termo II da argumentação é valorizado perante o termo I, visto como erro ou equívoco. Seguindo essa metodologia, podemos dar a seguinte configuração tanto ao discurso deweyano quanto ao rousseauniano acerca da sociedade, associando às suas teses os conceitos compreendidos pelo termo II, em detrimento dos que se identificam com o termo I:

$\begin{array}{lllll}\text { Termo I } & \text { Particular } & \text { Interesses privados } & \text { Competição } \\ & \text { Coletivo } & \text { Interesses compartilhados } & \text { Cooperação }\end{array}$

Apesar dos condicionantes de época que os separam, podemos concluir que o discurso de ambos os filósofos, utilizando estratégias argumentativas comuns, é pautado na crítica à ordem social de seus respectivos contextos históricos, expressando com vigor a proposição de um novo modo de organizar a coletividade, o modo democrático, uma forma de vida social fundamentada na livre comunicação, na igualdade e na liberdade de pensamento e ação dos indivíduos, em prol do compartilhamento de interesses. A educação atual é uma decorrência inescapável do modo de vida instituído em uma sociedade que não se organiza segundo esses princípios, o que impõe urgência à renovação das práticas pedagógicas, como veremos a seguir.

\section{A proposição de novas práticas pedagógicas}

Segundo Dalbosco (2010, p. 67), a proposta educacional deweyana advém de uma crítica ao predomínio de métodos escolásticos na educação. Em Democracia e educação, Dewey (1959b, p. 58) explica que, seguindo tais métodos, educar se reduz 
a um "processo de preparação" para os deveres e os benefícios ocasionados pela vida adulta. A criança é vista como um ser incompleto, que precisa ter seu vazio preenchido, motivo pelo qual suas necessidades, suas energias e seus impulsos, tão caros a seu desenvolvimento atual, são negligenciados em detrimento da valorização de sua condição futura.

Semelhante contrariedade é apresentada por Rousseau, que, segundo Dalbosco (2010, p. 50), é o precursor das críticas endereçadas àqueles métodos. Sua discordância incide sobre as ideias que, em sua época, defendiam a primazia da razão para dar início ao processo educacional infantil. O filósofo defende que esse processo seja orientado segundo as particularidades da criança, o que impõe a necessidade de conduzi-la do "país das sensações até as fronteiras da razão pueril" (ROUSSEAU, 2004, p. 203), dando prioridade à experiência.

Para Rousseau, tal qual para Dewey, renovar a educação é condição imprescindível para a criação de uma sociedade fundamentada em preceitos democráticos. Para renovar a educação, faz-se necessário adotar bases filosóficas novas, capazes de formar o homem e o cidadão que responderão pela transformação da ordem social; segundo Dalbosco (2010, p. 53), a experiência é a noção central de suas teses. Em Emílio, o filósofo genebrino afirma que seu projeto de educação natural é firmado na experiência do aprendiz, responsável por antecipar as lições a serem aprendidas (ROUSSEAU, 2004, p. 48). A pedagogia rousseauniana prevê a "experimentação concreta", sem a qual as crianças não expõem suas sensações e emoções e não vivenciam situações que fornecem os elementos que precisam para viver e bem julgar a sociedade na qual paulatinamente se inserem (PAIVA, 2007, p. 84).

Nessa argumentação, é possível notar que os dois pensadores operam a desqualificação da educação praticada em suas respectivas épocas. Essa estratégia argumentativa - a mesma que, segundo vimos na seção anterior deste trabalho, é utilizada na crítica à sociedade - tem o intuito de valorizar a apresentação de concepções inovadoras, em oposição às que são usualmente aceitas. As objeções ao método escolástico apresentadas por Rousseau e por Dewey têm o propósito de preparar a audiência para a tese alternativa, uma educação baseada na experiência.

Dewey apresenta uma nova definição de experiência: "experiência consiste primariamente em relações ativas entre um ser humano e seu ambiente natural e social" (1959b, p. 304, grifos do autor). A conexão que se estabelece entre a ação de um indivíduo sobre seu ambiente e o que acontece em seguida, a ação do ambiente sobre o indivíduo e o que ele faz em resposta, é precisamente o que confere significação aos atos e às coisas para esse mesmo indivíduo, possibilitando-lhe conhecer a si mesmo e o mundo em que vive (1959b, p. 301). 
Essa definição impõe uma definição igualmente nova de educação: educar é propiciar "reconstrução ou reorganização da experiência que esclarece e aumenta o sentido desta e também nossa aptidão para dirigirmos o curso das experiências subsequentes" (DEWEY, 1959b, p. 83, grifo do autor). A novidade dessa definição consiste em contrariar as duas concepções que até então disputavam as disposições da audiência: a educação como "desdobramento do interior para o exterior de faculdades latentes" e a educação como "formação do exterior para o interior" (1959b, p. 82-83).

Rousseau também apresenta uma definição inovadora em Emílio: a "educação é uma arte" (2004, p. 9) que fornece tudo o que necessitamos durante a vida. Para que esse objetivo se efetive, três modalidades educacionais devem operar em conjunto: a "educação da natureza" é responsável pelo "desenvolvimento interno de nossas faculdades e de nossos órgãos", sendo independente dos seres humanos; a "educação dos homens", caracterizada pelo "uso que nos ensinam a fazer desse desenvolvimento", é dirigida pela ação humana, mas não totalmente, pois não se pode controlar todas as situações da vida do educando; e a "educação das coisas", que depende dos seres humanos em alguns aspectos, corresponde à "aquisição de nossa própria experiência sobre os objetos que nos afetam” (2004, p. 11).

Dessas definições apresentadas pelo filósofo, a mais complexa é a da "educação pelas coisas". Dalbosco (2011, p. 174) explica que, para sua compreensão, faz-se necessário considerar que Rousseau concebe a experiência no sentido epistemológico, tal como os demais empiristas, mas ultrapassa esse significado ao associá-la à "esfera do agir humano em sua dimensão ético-pedagógica", o que significa que a educação deve considerar as necessidades, os limites e as possibilidades naturais da criança, valorizando sua relação com o ambiente e com os objetos que a cercam.

A nova definição de experiência trazida por Rousseau é diretamente relacionada à sua definição de educação, uma vez que se pode considerar uma criança educada quando ela sabe lidar com as situações favoráveis e desfavoráveis da vida; na infância, a "verdadeira educação consiste menos em preceitos do que em exercícios" (2004, p. 15), devendo ocorrer pela experiência. O filósofo genebrino recomenda que a educação da infância seja pautada, prioritariamente, em exemplos e ações concretas, não em discursos, pois os pequenos podem esquecer o que lhes foi dito, mas certamente não esquecem as experiências que viveram (2004, p. 107).

Como se pode observar, os dois filósofos apresentam as suas respectivas proposições educacionais utilizando o recurso da definição, a exemplo do que vimos anteriormente neste trabalho, no que tange a suas propostas para uma nova sociedade. Em Democracia e educação, encontra-se o uso dessa mesma estratégia discursiva na teorização acerca das noções de pensamento e problema, fundamentais na 
concepção educacional deweyana. Essa teorização foi formulada inicialmente em Como pensamos (1969a), obra de 1910 em que Dewey define pensamento reflexivo como uma "espécie de pensamento que consiste em examinar mentalmente o assunto e dar-lhe consideração séria e consecutiva" (1959a, p. 13). O pensar reflexivo liberta os indivíduos de ações comandadas pelos impulsos e pela rotina, tornando-os aptos a conduzir suas atividades com cautela e planejamento, tendo sempre a consciência de um fim a ser alcançado. A reflexão acentua a intencionalidade, pois "converte uma ação puramente apetitiva, cega e impulsiva, em ação inteligente" (1959a, p. 26, grifo do autor).

Em Democracia e educação, Dewey reafirma essas definições e enfatiza que cabe à educação desenvolver nos educandos "a melhor maneira de pensar" (1959b, p. 167-168), que é o pensamento reflexivo, único meio capaz de aprimorar constantemente o processo de ensino, por instigar a reflexão e submetê-la à avaliação permanente. A experiência reflexiva tem início quando o aprendiz é colocado diante de problemas, mas problemas verdadeiros, significativos para ele, surgidos no decorrer do processo educativo e oriundos de sua experiência em alguma situação real de vida, problemas que tenham suscitado dúvidas genuínas, curiosidade ou desejo por descobrir algo. É o tipo de problema que requer uma investigação, envolvendo a busca por informações, a elaboração de hipóteses e, por fim, a ação destinada a sanar a dúvida inicial (1959a, p. 170-171).

Com essas definições, Dewey se contrapõe às noções tradicionais de pensamento e problema, termos usualmente concebidos, respectivamente, como processo passivo de recepção de conteúdos prontos e como obstáculo ao aprendizado. Essas formulações se aproximam das ideias de Rousseau (2004, p. 121), para quem a criança vive experiências que envolvem o pensamento e o raciocínio, mas, ao contrário do que se pensa, o raciocínio infantil é bastante satisfatório, se o compreendermos em associação com os interesses e as vivências atuais e sensíveis da infância. É equivocada a prática de obrigar as crianças a pensar sobre saberes que os adultos julgam importantes, e que elas ainda não são capazes de entender.

Para Rousseau (2004, p. 149), a arte de educar pela experiência pressupõe que o pensamento é um aprendizado que se viabiliza pelo exercício dos órgãos e dos sentidos da criança, que são as ferramentas de sua inteligência. $\mathrm{O}$ aluno assim formado está sempre em movimento, brinca, fala, observa, conhece diferentes objetos e realidades; ele não sabe as lições inventadas pelos adultos, mas age, planeja, avalia e pensa sobre tudo o que diz respeito a si mesmo. Suas ações estão sempre relacionadas a seu pensamento, razão pela qual o agir e o pensar desenvolvem-se conjuntamente (2004, p. 139). 
Na proposição rousseauniana de educação pela experiência, a curiosidade é despertada por esse desenvolvimento conjunto, direcionando a atenção do aprendiz para os fenômenos naturais mediante a formulação de problemas a serem resolvidos no decorrer das situações vivenciadas. Rousseau (2004, p. 216) aconselha que o professor não deve se antecipar com o propósito de saciar a curiosidade da criança, como se faz na educacional tradicional, quando o mestre oferece respostas a questões por ele mesmo criadas. Nessa proposta, que é precursora das ideias deweyanas, o professor deve criar situações problemáticas em sintonia com a inteligência e os interesses do aluno, deixando que o próprio aluno as resolva, e assim o conhecimento adquirido será parte inseparável de sua compreensão do mundo.

A análise retórica permite identificar características comuns às formulações discursivas de Rousseau e Dewey, no que diz respeito à proposição de novas práticas pedagógicas. A argumentação de ambos é organizada por uma dissociação nocional que opõe passividade à atividade, termo I e termo II, respectivamente, privilegiando o segundo como o único meio pelo qual os educandos podem ser formados como indivíduos e cidadãos, tornando-se, assim, capazes de contribuir para a reorganização da sociedade existente e a construção de um modo de vida democrático.

\section{Uma metáfora comum}

Boto (2002) sugere que, ao escrever Emílio, a intenção de Rousseau não era promover a transposição fiel de suas ideias para a prática, mas incentivar que determinados princípios fossem utilizados como "escala" para avaliar e transformar a educação. Por isso, o livro pode ser visto como "um relato, uma metáfora, uma suposição ou categoria operatória" (2002, p. 370). Podemos examinar as proposições rousseaunianas como expressão da metáfora que Mazzotti (2002, p. 128) denomina "percurso indeterminado", em oposição a "percurso determinado", ambas decorrentes da analogia entre a atividade de educar e a atividade de caminhar; educar é ir de um estado de "menor educação para outro, considerado superior ao primeiro por ser provido de mais educação", de modo semelhante a quando nos deslocamos fisicamente de um lugar a outro.

A peculiaridade do percurso indeterminado reside em assumir que o caminhar é orientado por contingências, sendo o caminho construído no decorrer da própria atividade. Nessa modalidade de deslocamento, os caminhantes não consideram desejável - nem possível, muitas vezes - estabelecer com exatidão o trajeto, muito menos o lugar aonde vão chegar. Por transposição metafórica, o conhecimento é algo que se realiza no momento em que o sujeito se relaciona com o objeto, razão 
pela qual o ensino deve privilegiar as deliberações do aprendiz e do mestre, ambos compartilhando o mesmo percurso como únicos responsáveis pela superação dos obstáculos e pela determinação dos resultados do processo.

$\mathrm{Na}$ crítica que faz à educação vigente, o filósofo genebrino afirma que os mestres que ensinam a ciência sem considerar os interesses atuais do aprendiz formam pessoas seduzidas pelo ato de conhecer, envolvidas na busca frenética por mais e mais saberes, mas que acabam por não possuir saber algum, de modo semelhante a quando uma criança corre na praia colhendo conchinhas: ela começa guardando algumas, mas depois, tentada pelas outras, vai abandonando aquelas, "até que, esgotada pela multidão de conchas e já não sabendo o que escolher, acaba jogando tudo fora e voltando de mãos vazias" (ROUSSEAU, 2004, p. 222). Essa ilustração visa defender que a função do professor é avaliar e selecionar os conhecimentos que devem ser ensinados ao aprendiz, segundo as necessidades próprias da idade, para que ele não se perca em meio a saberes inúteis.

Isso não implica desprezo pela adoção de um método pedagógico, mas essa ferramenta não pode ser desenhada antecipadamente, pois a sua realização depende das circunstâncias em que é utilizada. Em Rousseau (2004, p. 72), essa questão diz respeito ao fato de ser impossível determinar a duração da vida de uma pessoa; embora normalmente se atribua a ela uma extensão determinada e se estabeleça certo tempo para cada fase, o viver é caracterizado pela incerteza. Por isso, a educação deve ser ministrada de modo que o aprendiz desfrute as experiências do presente. Os professores devem se preocupar com o ponto inicial do processo educativo, o único passível de ser conhecido, não havendo como prever sua outra extremidade, ou a sua direção, uma vez que o progresso do indivíduo depende de características ímpares - seu intelecto, suas aptidões, preferências, necessidades, dedicação, etc. Nunca sabemos até aonde uma pessoa pode chegar, o momento em que não mais terá condições de progredir (ROUSSEAU, 2004, p. 48).

Dalbosco (2011, p. 161) esclarece que essa indeterminação se explica por Rousseau considerar que as capacidades intelectuais e morais dos indivíduos são desenvolvidas no âmbito das relações sociais mantidas durante a vida; sendo impossível aquilatar com antecedência o caráter dessas relações, torna-se também impossível determinar o percurso de sua educação. A ideia de vida e educação como processos indissociáveis e imprevisíveis também se apresenta em Democracia e educação, quando Dewey define que "educação é desenvolvimento", o que requer compreender que "vida é desenvolvimento e que o desenvolver-se, o crescer é a vida" (1959b, p. 53).

Educar, portanto, é orientar as energias do aprendiz, no intuito de promover hábitos destinados à realização de atividades práticas, ao surgimento de interesses 
e à constituição de finalidades, sabendo que a criança possui capacidades inerentes àquela fase de sua vida. Para cumprir essa tarefa, o mestre deve estar em posse de um método, evidentemente, mas é preciso entender que o ambiente em que se processa a vida está em constante movimento, trazendo sempre novos estímulos que reorganizam e reorientam aquelas energias. A desconsideração desse preceito conduz à estagnação do crescimento, levando a condutas passivas de acomodamento às condições atuais (DEWEY, 1959b, p. 53-54).

Dewey (1959b, p. 54) acrescenta que tanto a criança quanto o adulto estão em desenvolvimento, e a diferença entre eles não resulta de o processo do primeiro estar em andamento e o do segundo estar concluído. O que os distingue são as formas de seus respectivos processos na dependência das condições vividas individualmente. Na infância, a resolução de problemas nas situações de ensino é responsável por desencadear o desenvolvimento de habilidades que contribuem para o crescimento e a maturidade, aproximando a criança da vida adulta. No adulto, o desenvolvimento é provocado pela curiosidade e pela possibilidade de mudanças no modo de pensar.

O equívoco geralmente cometido na educação das crianças consiste em considerar que a infância é um período de imaturidade, o que se deve ao entendimento errôneo de que desenvolvimento é sinônimo de preencher um suposto vazio entre o ser imaturo e o ser adulto. A fase adulta é concebida como uma medida, um padrão estático e ideal a ser atingido pelos educandos, o que confere características negativas à criança, julgando-a pelo que lhe falta para alcançar a idade adulta. Essa ideia supõe também que os adultos não têm mais o que aprender e crescer (DEWEY, 1959b, p. 44-45); supõe também que o desenvolvimento é uma "evolução ou marcha" para um fim determinado, uma simples adaptação do aprendiz a um ambiente imutável. Os métodos de ensino mecanizados e inflexíveis, que impõem o aprendizado de habilidades automáticas, têm essas concepções por base (DEWEY, 1959b, p. 54).

De modo semelhante ao proposto por Rousseau, a proposição educacional deweyana sugere que o ensino seja pautado na promoção de mais desenvolvimento, em sintonia com a maturidade, as necessidades e possibilidades atuais do aprendiz. A educação não deve se subordinar a outra finalidade que não seja a de mais educação; que o indivíduo seja continuamente educado, mesmo após deixar a escola, e que a escola o prepare não para reproduzir os conteúdos que o professor considera necessários para o futuro, mas para saber ordenar as suas energias para seu constante desenvolvimento. Dewey acredita que o "mais belo produto da eficiência escolar" (1959b, p. 55) é a capacidade de aprender com a vida, não a habilidade em seguir o rumo traçado pelo mestre. O percurso determinado, imposto pelo adulto 
à revelia da criança, é uma "ociosa fantasia" que subordina a vida a imagens que só existem em cabeças que se deixam dominar pela ilusão (DEWEY, 1959b, p. 55).

A metáfora percurso indeterminado, que transporta a ideia de que o processo educativo não pode ter seus meios e fins previamente estabelecidos, por ser a educação intimamente associada à vida, serve para compreendermos tanto o discurso de Dewey quanto o de Rousseau. Essa metáfora, bem como os discursos pedagógicos por ela representados, veicula um sentido de incerteza que afronta diretamente as concepções educacionais que se pautam na crença de que só podem educar por intermédio de planos e práticas inflexíveis, entendendo ser esse o modo de formar o aluno para que ele cumpra, quando adulto, se não ainda como criança, funções úteis para ele mesmo e para a sociedade.

\section{Considerações finais}

Não esperamos ter esgotado neste trabalho todas as possibilidades de análise acerca da presença de Jean-Jacques Rousseau nas concepções filosóficas e educacionais de John Dewey. A continuidade de nossa investigação poderá identificar outros pontos de convergência, como também de discordância, entre ambos. Por ora, podemos elaborar algumas reflexões sobre a possibilidade de posicionar tanto o filósofo genebrino quanto o pensador americano em confronto com a ideia, enfaticamente afirmada em discursos atuais, de que a educação é um bem - ou uma mercadoria - que deve servir não à fruição da vida, no momento mesmo em que ela acontece, mas ao propósito de garantir à pessoa um futuro seguro, representado por sucesso profissional e ascensão na hierarquia social, e à sociedade, progresso econômico e bom posicionamento na ordenação global das nações (BIESTA, 2013).

O livro Democracia e educação, escrito há pouco mais de 100 anos, parece ter antecipado o avanço dessa ideia, hoje tão propalada, e a ela se opôs radicalmente. Esperamos ter mostrado neste trabalho que, para elaborar sua obra, Dewey incorporou importantes concepções rousseaunianas, desenvolvendo-as por meio de recursos argumentativos muito próximos aos de Rousseau. Isso nos permite sugerir que ambos pertencem a uma tradição discursiva que se caracteriza por exprimir descontentamento ante a realidade existente e, ao mesmo tempo, sensível disposição para propor novos caminhos para a educação.

Segundo Crick (2010), essa tradição deve sua origem aos sofistas, cuja atuação na Grécia Clássica visava à formação de juízos comumente acordados por meio da investigação continuada, enfatizando o problema como fonte do conhecimento que se obtém por intermédio da inteligência e da persuasão. Crick (2015) defende que se pode identificar em Dewey uma pedagogia retórica, cujo traço mais marcante é 
a valorização do indivíduo no processo de sua educação, o que viabiliza a liberação de seus impulsos para desenvolver suas capacidades de deliberar e agir de modo inteligente. Essa pedagogia, que em muito se assemelha à proposta pelo filósofo genebrino, tem a mesma radicalidade que se encontra no conceito deweyano de democracia, que conta com a propensão do homem para a comunicação, a deliberação e a persuasão, com o propósito de elaborar consensos sobre assuntos de interesse público.

Como tudo na vida, os temas de interesse da coletividade seguem percursos indeterminados, razão pela qual a educação não pode ser concebida como caminho reto e sem percalços, nem como conjunto fixo de habilidades a serem aprendidas de uma só vez e para sempre, a serviço de fins externos ao desenvolvimento atual do aprendiz. O que a escola pode fazer é organizar um ambiente de vida compartilhada, que ofereça condições para os alunos expressarem as suas potencialidades individuais e experimentarem variados trajetos na solução de problemas genuínos. Esse é o mais relevante e belo legado de Democracia e educação, como também de Emílio.

\section{Notas}

1 As pesquisas que originaram este trabalho foram subvencionadas pela Fundação de Amparo à Pesquisa do Estado de São Paulo (Fapesp) e pelo Conselho Nacional de Desenvolvimento Científico e Tecnológico (CNPq).

2 Rousseau (2003, p. 84) não espera que todos participem efetivamente na elaboração e na execução dos norteamentos legais, uma vez que a perfeição, segundo ele, é digna somente dos deuses.

3 Como vimos anteriormente, Rousseau discorre sobre o modo de governar, mas o faz à luz de uma definição de democracia.

\section{Referências}

AMARAL, Maria Nazaré Camargo Pacheco. Dewey: filosofia e experiência democrática. São Paulo: Perspectiva; Edusp, 1990.

BIESTA, Gert. Para além da aprendizagem: educação contemporânea para um futuro humano. Belo Horizonte: Autêntica, 2013.

ARISTÓTELES. Retórica. Bauru: Edipro, 2011.

BOTO, Carlota. A escola do homem novo: entre o Iluminismo e a Revolução Francesa. São Paulo: Unesp, 1996.

. Jean-Jacques Rousseau: biografia intelectual. Intérprete da política e da infância. $R e$ vista Educação, Série História da Pedagogia (Jean-Jacques Rousseau), São Paulo, n. 5, p. 6-17, dez. 2010. 
. História, verdade e virtude em Rousseau: pacto político e ética pedagógica. Revista de História das Ideias, Coimbra, v. 23, p. 317-364, 2002.

CAMBI, Franco. História da pedagogia. São Paulo: Unesp, 1999.

CRICK, Nathan. Compor a vontade de poder: John Dewey sobre a educação retórica para uma democracia radical. Educação e Cultura Contemporânea, Rio de Janeiro, v. 12, n. 28, p. 164-183, 2015 .

Democracy and rhetoric: John Dewey on the arts of becoming. Columbia: University of South Carolina, 2010.CUNHA, Marcus Vinicius. Experiência e afeto em Dewey: uma conexão orgânica. Revista Educação em Foco, Juiz de Fora, v. 20, n. 2, p. 251-266, jul./out. 2015.

Recontextualização e retórica na análise de discursos pedagógicos. In: SOUZA, Rosa Fátima; VALDEMARIN, Vera Teresa (Org.). A cultura escolar em debate: questões conceituais, metodológicas e desafios para a pesquisa. Campinas: Autores Associados, 2005. p. 179-207. DALBOSCO, Cláudio Almir. Educação natural em Rousseau: das necessidades da criança e dos cuidados do adulto. São Paulo: Cortez, 2011.

Pragmatismo, teoria crítica e educação: ação pedagógica como mediação de significados. Campinas: Autores Associados, 2010.

DEWEY, John. Como pensamos: como se relaciona o pensamento reflexivo com o processo educativo - uma reexposição. São Paulo: Nacional, 1959a.

Democracia e educação: introdução à filosofia da educação. São Paulo: Nacional, 1959b.

MAZZOTTI, Tarso Bonilha. A metáfora percurso no debate sobre políticas educacionais no Brasil contemporâneo. In: VALE, José M. Ferreira et al. (Org.). Escola pública e sociedade. São Paulo: Saraiva, 2002. p. 124-132.

PAIVA, Wilson Alves. A formação do cidadão na obra de Jean-Jacques Rousseau. Fragmentos de Cultura, Goiânia, v. 17, n. 1/2, p. 77-92, jan./fev. 2007.

PERELMAN, Chaïm; OLBRECHTS-TYTECA, Lucie. Tratado da argumentação: a nova retórica. São Paulo: Martins Fontes, 2005.

PISSARRA, Maria Constança Peres. Rousseau: a política como exercício pedagógico. São Paulo: Moderna, 2002.

ROUSSEAU, Jean-Jacques. Discurso sobre as ciências e as artes. São Paulo: Martins Fontes, 2002a.

Discurso sobre a origem e os fundamentos da desigualdade entre os homens. São Paulo: Martins Fontes, 2002b.

. Emílio ou da educação. São Paulo: Martins Fontes, 2004.

. O contrato social. São Paulo: Martins Fontes, 2003. 